neuroimaging (brain and neuroaxial) are advisable, especially if the patient develops any neurological symptoms.

\section{AXILLARY BRANCHIAL PLEXUS BLOCK IN A WOMAN AT 34 WEEKS OF GESTATION FOR NON-OBSTETRIC DAY- SURGERY - A CASE REPORT}

E Nikouli, G Karras*, V Koutsis, F Arampatzidou, B Kiamiloglou. 'Sismanogleion' General Hospital of Komotini, Komotini, Greece

\subsection{6/rapm-2021-ESRA.113}

Background and Aims We report an axillary branchial plexus block for surgical anaesthesia in a third-trimester parturient without other comorbidities. The 30-year-old woman (34 weeks) was scheduled for external fixation of her Colles' fracture (left) after a ground-level fall. The patient consented to the proposed awake regional block technique instead of general anaesthesia.

Methods We performed a multiple-injection peripheral nerve stimulation (PNS) technique with $0.5 \%$ ropivacaine $30 \mathrm{~mL}$, $1 \%$ lidocaine $10 \mathrm{~mL}$, with 1:400.000 epinephrine as intravascular marker. The patient was placed in left lateral decubitus position with the arm to be blocked placed at a right angle to the body and the elbow flexed to 90 degrees. Skin anesthesia was also applied for the placement of an arm tourniquet. Standard monitoring was placed, supplemental oxygen was administered, baseline fetal heart rate was obtained by our obstetrical colleague. No sedatives or analgesics were administered during either procedure.

Results Our block was well tolerated and produced reliable and adequate anaesthesia during the 50-minute surgical procedure. No respiratory compromise was observed. The block lasted approximately $10 \mathrm{~h}$ and no pain was reported for $6 \mathrm{~h}$. In post-anaesthesia care unit, she had normal respiration, she did not complain about pain, and our obstetric colleagues reassessed the fetal heart rate without any new concerns. The patient was discharged the next day.

Conclusions We successfully performed adequate regional anaesthesia, using a reliable and safe technique, avoiding hemidiaphragm paralysis. This non-obstetric surgery in the parturient amplified the necessity of neuraxial anaesthesia, as branchial plexus block can be ideal for upper extremity pathology.

\section{PHEOCHROMOCYTOMA AND C-SECTION - IS REGIONAL ANAESTHESIA THE SOLUTION FOR THIS DANGEROUS COMBINATION?}

LA Montenegro Ledo, TR Alves Martins*, AR Santos Almeida Silva, MP Sanches Lucas, EC Pereira. Hospital Garcia de Orta, Almada, Portugal

\subsection{6/rapm-2021-ESRA.114}

Background and Aims Pheochromocytoma is a rare cause of hypertension during pregnancy, but it is one of the most threatening medical conditions for mother and fetus. Anaesthetic management for $\mathrm{C}$-section is challenging because it is associated with serious cardiovascular complications.

We report a successful case of c-section under combined spinal-epidural (CSE) anaesthesia in a pregnant patient with a pheocromocytoma.
Methods A 32 weeks pregnant women was referred to our hospital with persistently uncontrolled hypertension. During investigation, an abdominal MRI revealed a right-sided suprarenal mass suggesting a pheochromocytoma. Plasma and urine metanephrines were increased, confirming the diagnosis. The remain study showed normal results.

At a multidisciplinary consultation was decided to do surgical resection of pheochromocytoma after elective C-section at 36th week.

Preoperative medical preparation included $\alpha$-blockade (doxazocin), beta-blockade (propranolol) and normalization of intravascular volume (high sodium diet).

Results Before induction, a central vein and artery were cannulated for hemodynamic monitoring.

A CSE anaesthesia was performed to minimize hypertensive crises. At subarachnoid space, it was administered $11 \mathrm{mg}$ of hyperbaric bupivacaine and $3 \mathrm{mcg}$ of sufentanyl. Rapid co-filling with 11 of ringer lactate, under pressure, was administer. Adequate anaesthesia level was guaranteed and patient remained hemodynamically stable, without need of vasoactive drugs. No intercurrences were recorded.

Multimodal analgesia was prescribed for post-operative period with epidural patient control analgesia.

Conclusions Meticulous anaesthetic management is crucial and the choice of anaesthetic technique plays a decisive role in outcome of patient.

Regional anaesthesia presented as an effective technique either in blunt surgical stress and to provide post-operative analgesia.

\section{QUESTIONNAIRE SURVEY OF SATISFACTION WITH LABOUR NEURAXIAL ANALGESIA - COMBINED VERSUS EPIDURAL}

S Carvalho, A Carrão, I Ferraz*, C Castanheira, M Ghira. Hospital Beatriz Ângelo, Loures, Portugal

\subsection{6/rapm-2021-ESRA. 115}

Background and Aims Both combined spinal-epidural and epidural techniques are shown to provide effective pain relief during labour and there appears to be little basis for offering one technique over the other. The aim of this study was to evaluate if there is any difference between the techniques regarding overall maternal satisfaction.

Methods We conducted a retrospective questionnaire survey to women up to 3 days after delivery, between July and September 2020. The primary outcome was the degree of satisfaction (with a numeric rating scale from 0 to 10 ). Secondary outcomes were pain relief (with a numeric rating scale from 0 to 10) and side effects. Outcomes after labour analgesia with epidural were compared with combined spinal-epidural technique. Statistical analysis was performed using SPSS ${ }^{\circledR}$ software (version 22).

Results A total of 213 women answered the questionnaire, of which $51.6 \%$ had a combined spinal-epidural and $48.4 \%$ epidural technique. The median degree of satisfaction was 10 $[9 ; 10]$ after combined spinal-epidural and $10[8 ; 10]$ after epidural (p-value $<0,05$; figure 1). Pain relief was higher after combined spinal-epidural ( $\mathrm{p}$-value $<0,05$; figure 2 ), despite an incidence of pruritus of $60 \%$ compared with $42 \%$ after epidural (p-value <0,05). About $49 \%$ of women reported no side effects after epidural versus $31 \%$ after combined spinal- 